\title{
Tetris: a geometria em jogo
}

\section{Isabela Oliveira Soares, ${ }^{1,3}$ Juscileide Braga de Castro ${ }^{2,3}$}

${ }^{1}$ Licencianda em Pedagogia da Universidade Federal do Ceará e bolsista do Programa de Iniciação à Docência (PID) - Faculdade de Educação, Fortaleza - CE - Brasil

${ }^{2}$ Docente da Universidade Federal do Ceará - Faculdade de Educação, Departamento de Teoria e Prática do Ensino (DTPE), Fortaleza - CE - Brasil

${ }^{3}$ Membros do Grupo de Pesquisa e Produção de Ambientes Interativos e Objetos de Aprendizagem - PROATIVA, UFC

isabela.o.soares@gmail.com; juscileidedvirtual.ufc.br

\begin{abstract}
This work aims to present an experience with the use of the game Tetris for the teaching of geometry in the early years; And analyze their potentialities and contributions. For this, an investigation was carried out in two moments: (1) study of digital resources that could be used to work geometry contents in the initial years of Elementary School and (2) workshop with 20 students of the 7th semester of the Pedagogy course In which it was possible to analyze, through practical activity, the contributions and limitations of the chosen game. The results indicate that Tetris can contribute to the teaching of geometry, and the workshop helped to incorporate into the teaching practice of these future teachers the use of technology in order to perceive the game as a useful tool for their profession.
\end{abstract}

Resumo. Este trabalho tem como objetivos apresentar uma experiência com o uso do jogo Tetris para o ensino de geometria nos anos iniciais; $e$ analisar suas potencialidades e contribuições. Para isso, realizou-se uma investigação em dois momentos: (1) estudo de recursos digitais que pudessem ser utilizados para trabalhar conteúdos de geometria nos anos iniciais do Ensino Fundamental e (2) oficina com 20 estudantes do $7^{\circ}$ semestre do curso de Pedagogia em que foi possível analisar, por meio de atividade prática, as contribuições e limitações do jogo escolhido. Os resultados indicam que o Tetris pode contribuir no ensino de geometria, tendo a oficina ajudado a incorporar à prática docente destes futuros professores o uso de tecnologia, de modo a perceber o jogo como ferramenta útil à sua profissão.

\section{Introdução}

Nos últimos anos têm se observado a implementação de políticas públicas brasileiras com vistas à inserção e apropriação das tecnologias digitais nos espaços escolares, buscando criar/desenvolver uma cultura, entre os professores, de integração de tecnologias digitais à dinâmica das ações pedagógicas [Almeida 2008; Maia e Barreto 2012]. 
Dentre as ações mais recentes do PROINFO $^{1}$, importa citar o Programa Um Computador por Aluno (PROUCA), criado pela lei $\mathrm{N}^{\mathrm{o}} 12.249$, de 10 de junho de 2010, instituindo o Regime Especial de Aquisição de Computadores para uso Educacional (RECOMPE) que regulamenta as formas de aquisição, pelo poder público, dos laptops educacionais. Estes dispositivos de baixo custo passaram a proporcionar novas experiências pedagógicas e desvelar novas possibilidades para a educação, tais como a conectividade imersiva e a mobilidade, diferente dos computadores fixos (desktops) comumente utilizados em Laboratórios de Informática Educativa [Castro e Castro-Filho 2012].

Outros projetos e programas, seja de iniciativa privada ou governamental, têm beneficiado a população e possibilitado a inclusão digital por meio de laptops educacionais, tablets, kits multimídia, smartfhones, softwares educativos, tendo influenciado a vida das pessoas [Warschauer, 2006].

Nesse sentido, é indiscutível que as tecnologias estão cada vez mais presentes em atividades escolares, afetando e influenciando ações e relações humanas. No entanto, é preciso considerar que a maioria das experiências que as pessoas possuem com tecnologias digitais acontecem em ambientes extra-escolares e mesmo quando as utilizam em sala de aula, há discrepâncias do uso que se faz dentro e fora da escola.

Desta forma, entende-se que os professores precisam desenvolver uma cultura docente alinhada aos paradigmas emergentes da sociedade de informação [Castells 1999] e da cibercultura [Lemos 2010] contemplando o acesso e a apropriação de diversos bens culturais como: internet, sites, redes sociais e jogos; que devem ser explorados e percebidos como ferramentas úteis à sua profissão.

Utilizar recursos digitais do tipo jogo para facilitar a aprendizagem de conceitos, ancorados nos desafios e interesses que estes proporcionam aos jogadores, têm sido foco de alguns estudos nos últimos anos, já que jogos de videogame, de computadores, tablets e smartfhones, principalmente os que são voltados para o entretenimento, têm conquistado um grande espaço na vida de crianças, jovens e, inclusive, adultos.

Diante do exposto, levanta-se a seguinte questão: Os jogos de entretenimento podem ser usados em ambiente escolar para a compreensão de conceitos? Que contribuições e limitações podem ser observadas neste tipo de jogo?

Diante dessas questões, os objetivos deste trabalho são: [1] apresentar uma experiência com o uso do jogo Tetris ${ }^{2}$ para o ensino de matemática nos anos iniciais; e [2] analisar as potencialidades e contribuições do Tetris para o ensino de matemática.

Com base nos objetivos definidos e na problemática levantada, os resultados encontrados nesta pesquisa contribuem para: [1] socialização de experiências com o uso de tecnologias na escola; [2] constatação das potencialidades e limitações do Tetris no ensino de matemática.

Nas sessões seguintes, apresentar-se-á discussão sobre jogos de entretenimento e jogos educativos no ensino de matemática. Em sequência serão dispostos os procedimentos metodológicos da investigação, seguidos da discussão dos resultados e das considerações finais.

\footnotetext{
${ }^{1}$ Programa Nacional de Tecnologia Educacional, iniciado em 1997 e ainda vigente.

2 É um jogo eletrônico de quebra-cabeça, muito popular, desenvolvido por Alexey Pajitnov, Dmitry Pavlovsky e Vadim Gerasimov, e lançado em junho de 1984.
} 


\section{Os jogos de entretenimento e os jogos educativos no ensino de matemática}

Desde muito cedo as crianças são inseridas na cultura consumista de jogos, tendo a disposição um leque diferenciado de opções, o que contrasta com a passividade, cada vez mais presente, na escolarização dos estudantes. As atividades realizadas em sala de aula, no ambiente escolar, parecem desestimulantes em comparação às experiências que muitas destas crianças têm com o uso de diferentes tecnologias fora da escola, o que as permite "desenvolver um forte senso de autonomia e autoridade, e é exatamente isso que lhes é negado na escola" [Buckingham 2010, p. 44].

De fato, os estudantes preferem focar em jogos como Minecraft, Pokemon Go, dentre outros; que exigem, em muitas situações, tempo, disciplina e concentração; do que dedicar-se às aulas e às atividades escolares. Isso faz com que seja cada vez mais difícil para as escolas conquistarem a atenção e o interesse das crianças com aulas desanimadores e com o predomínio de atividades de repetição e de memorização.

O uso dos jogos ou games na educação tem sido controverso, se tornado um tema discutido entre pesquisadores, professores e pais. Se de um lado argumenta-se que tais jogos enfatizam a violência, os vícios, proporcionando poucas vantagens aos usuários; em outra visão, enfatiza-se os benefícios no campo cognitivo, cultural, social, afetivo, entre outros [Mattar 2010].

É importante verificar que durante a escolha de um jogo a criança desenvolve, por exemplo, o multiletramento, já que, muitas vezes, precisa avaliar ambientes complexos, com linguagens visuais e auditivas diferenciadas. É preciso considerar que alguns jogos envolvem uma extensa quantidade de atividades cognitivas: lembrar, testar hipóteses, prever e usar planos estratégicos; sendo que estas experiências são pouco valorizadas pela escola.

Além disso, as crianças aprendem as regras e os métodos mais eficazes de se utilizar o jogo por meio de tentativa e erro, da exploração, da experimentação e, mais recentemente, compartilhando experiências em fóruns virtuais. Desta forma, embora os usuários desses games, em geral, estejam profundamente imersos no mundo virtual, em jogos cooperativos como, por exemplo: Halo 3, Super Mario 3D World e Gauntlet; o diálogo e a interação com outros são cruciais [Carr et al. 2006].

Os jogos de entretenimento e os educativos divergem, especificamente, em duas funções: a lúdica - o jogo propicia a diversão, o prazer e até o desprazer, em alguns casos; e a educativa - o jogo ensina qualquer coisa que complete o indivíduo em seu saber, seus conhecimentos e sua apreensão do mundo.

Nos jogos de entretenimento o foco está voltado para a sua potencialidade lúdica, criando o que Huizinga (2012) chama de "círculo mágico", um espaço e tempo próprios ao jogo, aos quais pertencem apenas aqueles que entram voluntariamente e verdadeiramente no jogo. Logo, não se pode desprezar a capacidade educativa dos mesmos, especialmente como elementos da cultura, capazes de favorecer o aprendizado pela manipulação e representação simbólica da realidade, dentro da dimensão simbólica do jogo.

Todavia, conforme Brougère (2006, p.48) este envolvimento não deve ser considerado como condicionante: "Trata-se sobretudo de uma confrontação da qual a criança conserva determinadas significações, eliminando outras para substituí-las por novas significações". Neste sentido, têm-se uma aprendizagem ativa em que a criança não fica sujeita ao que está sendo imposto, mas às manipula e às transforma. No entanto, este mesmo autor, considera que, por vezes, o jogo educativo descaracteriza 
VI Congresso Brasileiro de Informática na Educação (CBIE 2017)

Anais do XXIII Workshop de Informática na Escola (WIE 2017)

algumas das principais características dos jogos: a improdutividade, o prazer, a liberdade e a frivolidade.

Ainda que o jogo educativo busque o equilíbrio entre as funções lúdicas e educativas, Costa (2009) explica que os jogos com finalidades pedagógicas não costumam ser divertidos como os jogos de entretenimento, justamente por direcionarem um objetivo externo ao jogo, o que inibe seu caráter lúdico. O autor ainda destaca que os jogos de entretenimento, quando usados com fins pedagógicos, podem ser mais efetivos.

Para Brom et al. (2011), os jogos, quando usados como ferramentas educacionais, podem ajudar no desenvolvimento de conhecimento e habilidades cognitivas, como na resolução de problemas, no desenvolvimento do pensamento estratégico, na tomada de decisão, propiciando a compreensão de conceitos, como os presentes na Matemática. Mayo (2007) e Del Blanco et al. (2009) defendem que o uso de jogos, especialmente sobre Matemática, ajudam a melhorar a aprendizagem dos estudantes. Isso acontece, pois, o acompanhamento que alguns jogos possibilitam durante as ações do estudante, como o feedback e a interatividade, podem indicar se as metas de aprendizagem estão sendo alcançadas.

Atualmente, com a popularização dos jogos é possível encontrá-los em consoles, na web, em computadores, em notebooks e smartphones. Essa popularização permite que as informações circulem mais facilmente, apontando estes dispositivos como uma possível alternativa para o uso pedagógico de mídias digitais [Brom et al 2011].

Os dispositivos móveis e seus aplicativos estão cada dia mais interessantes, acessíveis e intuitivos. A mobilidade proporcionada por eles podem possibilitar a exploração de situações de aprendizagem dentro e fora da sala de aula e da escola, a conectividade, a integração com outros dispositivos e com o currículo escolar, permitindo que o potencial do estudante seja trabalhado continuamente [Castro e Castro-Filho 2012].

A exploração do potencial dos jogos precisa ser feita pela escola, considerando o uso de metodologias que auxiliem a aprendizagem baseada em jogos. Para isso, defende-se a importância de professores vivenciarem novas experiências de ensino e de aprendizagem, desde a formação inicial. Na próxima seção serão explanados os procedimentos metodológicos da pesquisa.

\section{Procedimentos metodológicos da investigação}

Este trabalho integra as ações do Programa de iniciação à Docência (PID), edital $n^{\circ}$ 035/2016 da Pró-reitoria de Graduação da Universidade Federal do Ceará (PROGRADUFC). Esta investigação surgiu a partir das experiências vivenciadas nas disciplinas de Ensino de Matemática e de Ludopedagogia do Curso de Pedagogia da Faculdade de Educação da UFC (FACED/UFC), durante os semestres 2016.2 e 2017.1.

No primeiro semestre (2016.2) foi realizado um estudo de recursos digitais que pudessem ser utilizados para se trabalhar conteúdos do bloco Espaço e Forma e que atendessem aos anos iniciais do Ensino Fundamental. Os Parâmetros Curriculares Nacionais (PCN) de Matemática ressaltam não apenas os conceitos, mas, também, os conteúdos procedimentais e atitudinais. Sobre o bloco Espaço e Forma, os PCN destacam: a necessidade de desenvolver os conceitos geométricos de modo que os estudantes possam compreender, descrever e representar, o mundo em que vivem; a importância das noções geométricas voltadas para a observação, para a percepção de semelhanças e diferenças e identificação de regularidades [Brasil 1997]. 
Considerando todos estes aspectos, realizou-se buscas de recursos digitais educacionais em sites, repositórios nacionais e internacionais como: Banco Internacional de Objetos Educacionais (BIOE), Portal do professor, Núcleo de Computação aplicada (NOAS), Escola digital, dentre outros. No entanto, os recursos encontrados não atenderam as expectativas, visto que não favoreciam o desenvolvimento da competência, do raciocínio e do pensamento espacial/visual, por serem, em sua maioria, mecânicos, com pouca ou nenhuma interação (vídeos), ou, ainda, do tipo exercício e prática (quiz).

Durante as buscas realizadas, encontrou-se o Tetris, um videogame de quebracabeça, também denominado de tetraminó, por ser formado por quatro peças, ou quatro segmentos, dispostos segundo a regra dos poliminós, formando um total de cinco peças distintas, conforme Figura 01.
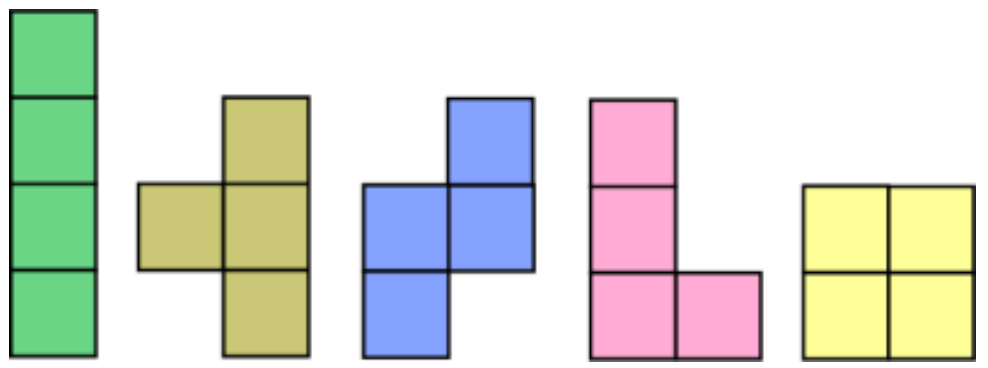

Figura 1. Disposições dos tetraminós

O objetivo do jogo consiste em empilhar as peças que descem a tela, que podem aparecer espelhadas e serem rotacionadas, numa velocidade que cresce gradativamente a cada nível de dificuldade, de forma a completar linhas horizontais. A medida que as linhas horizontais são formadas, as camadas superiores caem, o jogador ganha pontos e mais tempo de jogo. Caso não consiga formar as linhas horizontais e as peças cheguem ao topo da tela, a partida é encerrada.

Por ser um tipo de jogo de quebra-cabeça, o Tetris incentiva que o jogador observe e se aproprie da estruturas das peças de modo que forme a maior quantidade de linhas possíveis, para isso, é preciso analisar as peças que são anunciadas previamente, se necessário rotacioná-las, bem como observar a disposição de peças de mesma composição espelhadas, a fim de encaixá-las, apresentando um maior desafio ao usuário.

Assim, além de proporcionar o desenvolvimento de habilidades visuais e motoras, verificou-se, ainda, a possibilidade de trabalhar área a partir da composição e da decomposição de figuras, permitindo também diferenciar área de perímetro. Outra vantagem é que este jogo é bastante popular, podendo ser encontrado em praticamente todos os consoles de videogame, sistemas operacionais de microcomputadores, sites de jogos online, além de outros dispositivos como tablets e smartphones.

Considerando estas potencialidades constatadas no jogo Tetris, no segundo semestre (2017.1) foi planejada e aplicada uma oficina com 20 estudantes do $7^{\circ}$ semestre do curso de Pedagogia da UFC em que foi possível analisar, por meio de atividade prática, as contribuições e limitações do jogo escolhido.

Os dados apresentados na discussão dos resultados foram coletados por meio de diário de campo e screenshots realizados durante oficina, tendo sido analisados qualitativamente, a partir de triangulação de dados. A seguir apresentar-se-á a discussão dos resultados. 
VI Congresso Brasileiro de Informática na Educação (CBIE 2017)

Anais do XXIII Workshop de Informática na Escola (WIE 2017)

\section{Discussão dos resultados}

Para responder aos objetivos delimitados inicialmente, os resultados serão apresentados em duas seções: (1) apresentação de oficina realizada com o Tetris; e (2) Análise das potencialidades e limitações

\subsection{Apresentação da oficina}

A oficina contemplou conteúdos presentes no bloco Espaço e Forma e teve como objetivos: possibilitar que os estudantes do curso de Pedagogia da UFC reconhecessem diferentes formas geométricas de mesma área, mas com perímetros diferentes, permitindo a diferenciação do conceito de área e de perímetro; verificar a área de superfícies semelhantes a partir da composição e decomposição de figuras; além de apresentar recurso digital (jogo) para o trabalho de conteúdos da geometria.

Para a realização da oficina foi utilizado cartões quadrados para formar os tetraminós - feitos de cartolina; smartphones dos próprios estudantes; e o jogo Tetris instalado a partir da play store.

A oficina foi dividida em três momentos: (1) elaboração de hipóteses por meio da manipulação dos cartões quadrados - em equipe; (2) estabelecimento do desafio e jogo - individualmente; e (3) análise das imagens de tela salvas pelos alunos.

A aula iniciou a partir da seguinte questão: "Qual a diferença entre área e perímetro?". Embora a maioria dos estudantes soubesse diferenciar o conceito de área e de perímetro, um debate foi realizado, culminando nas seguintes hipóteses: (1) figuras de mesma área têm mesmo perímetro; (2) figuras de mesma área têm perímetros diferentes; e (3) não existe uma relação entre figuras de mesma área e seus perímetros. Para o estabelecimento destas hipóteses os estudantes dispuseram 4 quadrados de cartolina de diferentes formas (Figura 2).

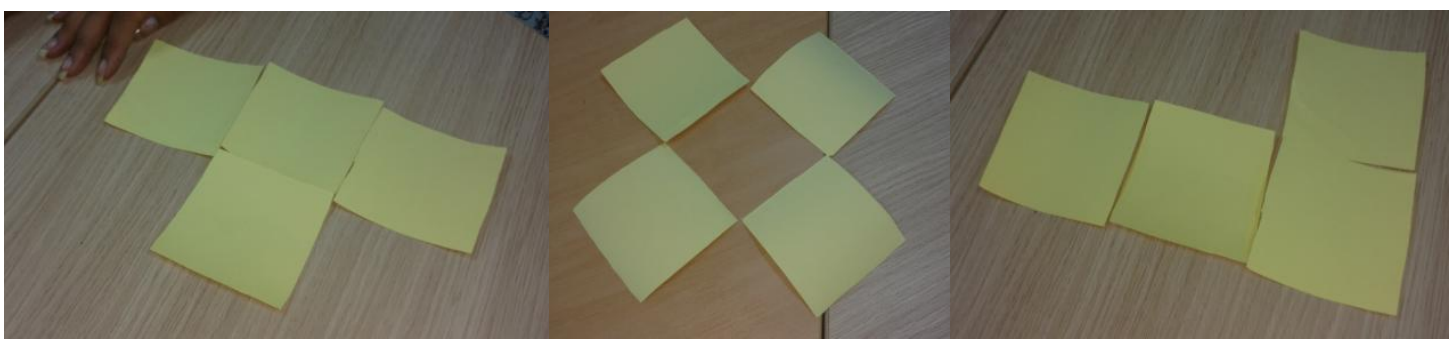

Figura 2. Exemplos de figuras formadas pelos estudantes

$\mathrm{Na}$ figura 2 é possível perceber que algumas das formas representadas pelos estudantes não formavam as figuras do Tetris (tetraminós). Desta forma, este momento foi aproveitado para verificação das possibilidades de construção e da análise das propriedades das figuras formadas, permitindo a compreensão de que algumas destas figuras não seriam adequadas para o objetivo do jogo: montar um quebra-cabeça encaixando peças bidimensionais de diferentes formatos capazes de girar sobre o próprio eixo em apenas quatro posições diferentes.

Após estas reflexões e elaborações de hipóteses, iniciou-se o $2^{\circ}$ momento da oficina, com os seguintes desafios:

- Jogar Tetris até contabilizar 4 linhas horizontais, ou mais, sem vazios;

- Fazer o print da tela sempre que formar 4 linhas horizontais completas, ou seja, sem vazios;

- Analisar quais peças foram usadas para formar as linhas horizontais;

- Realizar o print da tela, ao "perder o jogo", e analisar quais estratégias poderiam ser usadas para encaixar as peças. 
Embora tenha sido solicitado que os estudantes fizessem a instalação do jogo antes da oficina, cerca de metade dos alunos não fizeram, pois tiveram dúvidas sobre qual das opções deveriam instalar, já que a play store apresentava dezenas de opções deste jogo na versão gratuita. Foi explicado que qualquer versão poderia ser instalada, embora tenha sido recomendada a Brick Classic, por possibilitar, ao pausar, a visualização da tela com os blocos que já tinham sido empilhados.

Logo que os esclarecimentos foram feitos os alunos se mobilizaram para instalar o jogo. Durante este momento os estudantes mostraram-se imersos na experiência, chegando a criarem, espontaneamente, novas regras e desafios, incluindo uma competição de quem formava mais linhas "completas" deixando apenas a última coluna sem preencher.

De acordo com Huizinga (2012) é essa tensão, essa capacidade de envolvimento intenso, a característica mais essencial do jogo. Assim, quando o jogo acontece em grupos esse fator de tensão aumenta, aumentando também o envolvimento e o prazer em se ganhar.

Ao final do tempo de jogo, iniciou-se o $3^{\circ}$ momento da oficina, em que foram discutidos com a turma os conhecimentos mobilizados e os que poderiam ser mediados a partir do jogo Tetris, conforme serão discutidos a seguir.

\subsection{Análise das contribuições e limitações do Tetris}

Logo após encerrar o tempo de jogo $\left(2^{\circ}\right.$ momento $)$, foi solicitado aos estudantes que enviassem as imagens de telas salvas durante o jogo para que fossem exibidas e analisadas de forma coletiva. As Figuras 3 e 4 apresentam parte dos prints compartilhados por estudantes, logo após conseguirem atingir o objetivo estipulado no $2^{\circ}$ momento da oficina: jogar Tetris até contabilizar 4 linhas horizontais, ou mais, sem vazios. Nestas figuras pode-se verificar o uso de diferentes versões do Tetris, o que não atrapalhou a realização da atividade.

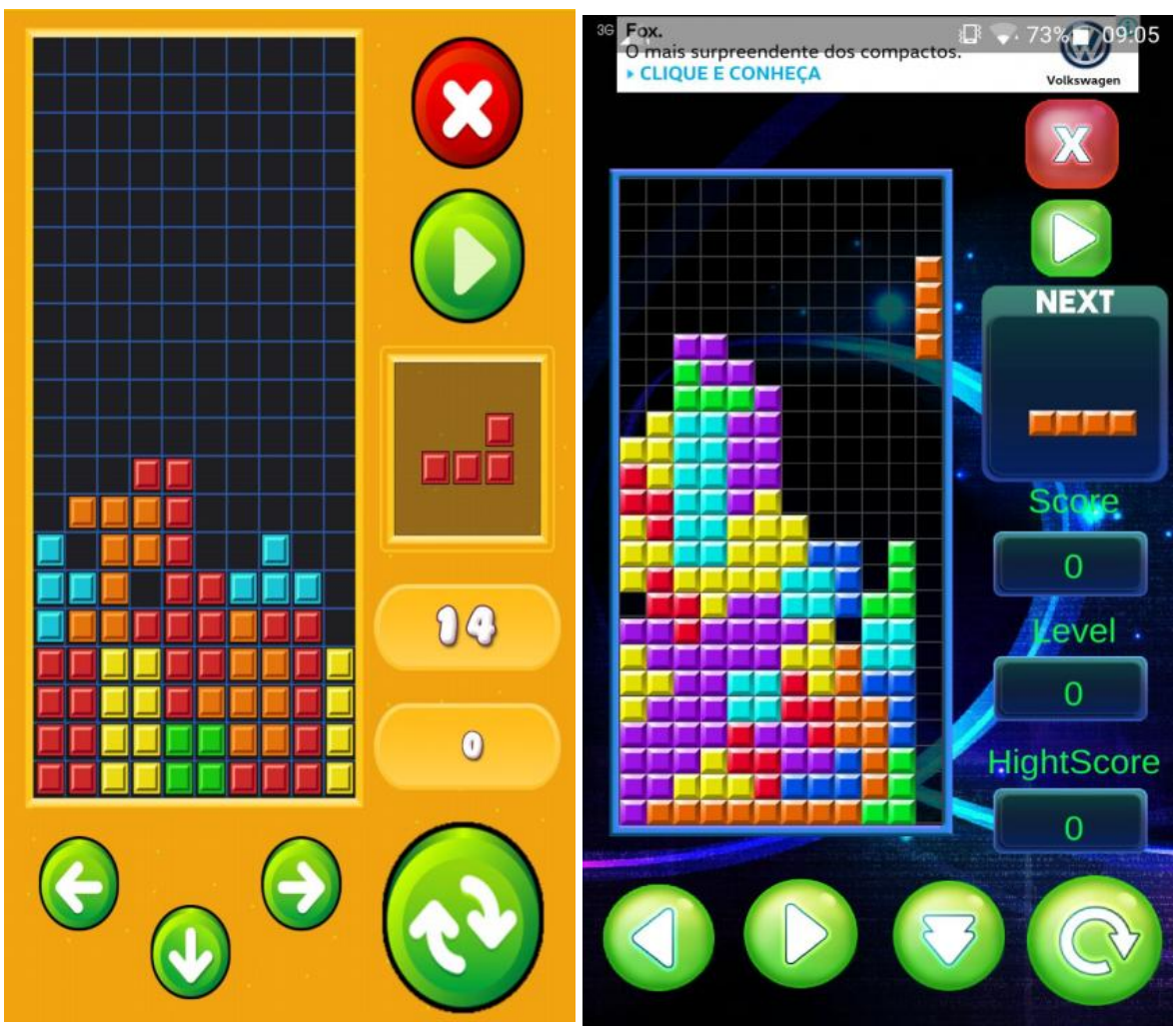

Figura 3. Screenshots compartilhados pelos estudantes Isabel e Igor, respectivamente 
$\mathrm{Na}$ Figura 3 verifica-se que Isabel $^{3}$ conseguiu fazer exatamente 4 linhas horizontais completas e que com a colocação da peça que viria em seguida (Tetraminó em forma de "L" vermelho) poderia conseguir mais uma linha completa, já que na sexta e na sétima linhas haviam espaços vazios. Também na Figura 3, constata-se que Igor ainda não tinha completado nenhuma linha quando fez o screenshot, mas com a peça que estava descendo e com a que viria em seguida, formaria 7 linhas horizontais completas.

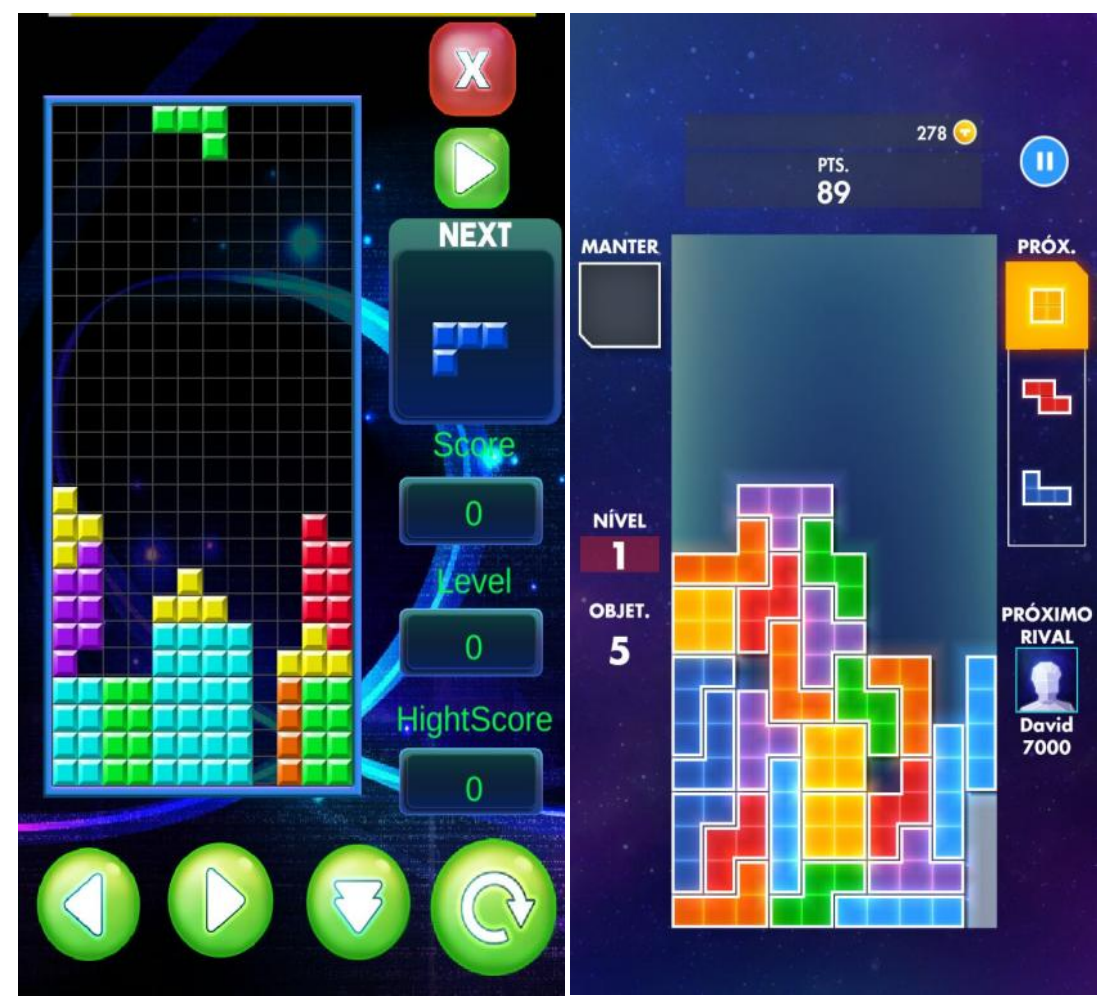

Figura 4. Screenshots compartilhados pelos estudantes José e Raquel, respectivamente

Na Figura 4, é possível visualizar que José não conseguiu completar as 4 linhas horizontais, mesmo considerando as peças que desceriam na sequência, necessitando para atingir o objetivo, de um tetraminó na forma de uma barra. Já Raquel fez o print logo que o tetraminó em forma de barra estava completando as 4 linhas, no entanto, mesmo que conseguisse outras peças para encaixar, não conseguiria obter mais pontos, devido ao espaço vazio na quinta linha (Figura 4).

Durante a socialização, foram feitas as seguintes questões para discussão: (1) O objetivo do desafio foi conquistado no momento representado na tela? (2) A peça seguinte, anunciada pelo jogo, formaria novas linhas? Quantas? (3) Havia espaços vazios no jogo em curso? $O$ que poderia ter sido feito para que os mesmos não existissem?

Estes questionamentos instigaram os discentes a pensarem em soluções dentro das regras do jogo, descartando hipóteses absurdas como, por exemplo, pensar em peças de formatos que não existiam. Neste momento foi possível analisar e perceber contribuições do jogo relacionadas com a capacidade de concentração, a noção espacial, e a percepção visual; corroborando com as recomendações dos PCN de Matemática de que a Geometria nos anos iniciais do Ensino Fundamental deve ser trabalhada

\footnotetext{
3 Por questões éticas, os nomes utilizados para designar os estudantes que participaram da oficina são fictícios.
} 
informalmente, a partir de manipulação e reflexão sobre atividades primordiais na construção conceitual [Brasil 1997].

Foi ainda compartilhado as diferentes estratégias adotadas individualmente para compor os espaços, sem deixar vazios, abordando, portanto, a noção de área e de perímetro. Percebeu-se que todos os tetraminós (Figura 1), possuíam a mesma área, mas perímetros nem sempre iguais. Com a imagem compartilhada e projetada foi possível remodelar o quebra-cabeça e verificar que a área está relacionada com o espaço que foi preenchido, para isso, foi feito a decomposição das figuras (circulado os tetraminós usados para compor os espaços), possibilitando refletir sobre as estratégias.

Percebeu-se que algumas das versões dos jogos tinham vantagem em relação a outras, se fosse usado, como critério, a maior área preenchida. Como pode ser visto nas Figura 3 e 4, as versões que Isabel e Raquel usaram tinha 10 colunas, enquanto que a de Igor e José possuía 12 colunas. Desta forma, mesmo que todos tivessem completado apenas as 4 linhas horizontais, a área preenchida seria diferente. No decorrer da discussão foi entendido que a existência de versões diferentes propiciou uma melhor compreensão da noção de área, uma vez que possibilitou o debate sobre o conceito que estava sendo abordado.

Costa (2009) explica que o jogo de entretenimento deve ser escolhido por favorecer a associação de ideias. Verifica-se que o Tetris é estruturado a partir de quadrados que compõem tetraminós, o que permite uma fácil associação com os conceitos da geometria, sendo, o jogo, portanto, o próprio objeto de conhecimento.

A falta de feedback e o fato de as linhas horizontais serem eliminadas à medida que eram completadas fazem parte deste tipo de jogo, afinal, trata-se de um jogo de entretenimento [Costa 2009]. Neste tipo de jogo é possível se divertir, se adaptar às regras, ou ainda, disfarçar a sua inadaptação ao mundo habitual [Huizinga 2012]. Tendo sido todos estes aspectos observados durante a oficina proposta.

As análises também promoveram a reflexão sobre a utilização deste jogo, como uma proposta didática, com estudantes dos anos iniciais do Ensino Fundamental, suscitando a adaptação da oficina de modo a atender as possíveis especificidades das crianças. Destacou-se a limitação de utilização deste jogo com deficientes visuais, por exemplo.

Ao final das discussões a oficina foi avaliada positivamente pelos 20 discentes do curso de Pedagogia que vislumbraram sua aplicação no segundo ciclo do Ensino fundamental, principalmente como forma de consolidar o conceito de área, por meio da composição e decomposição de figuras, e de perímetro. Evidenciaram ainda a união da tecnologia, resgatando um jogo utilizado na infância, e a ludicidade no ensino da matemática. A seguir serão expostas as considerações finais.

\section{Considerações finais}

Este artigo teve como objetivos: [1] apresentar uma experiência com o uso do jogo Tetris para o ensino de geometria nos anos iniciais; e [2] analisar as potencialidades e contribuições do Tetris para o ensino de matemática.

A experiência vivenciada na oficina permitiu que os discentes visualizassem as possibilidades metodológicas e didáticas que o jogo Tetris pode proporcionar no ensino de geometria, incorporando à prática docente destes futuros professores o uso de tecnologia, percebendo o jogo como ferramenta útil à sua profissão.

Como potencialidade pode-se destacar a possibilidade de uso no desenvolvimento de diversas sequências didáticas, que podem ser adaptadas às necessidades dos alunos. Já como limitação, ficou destacada nas reflexões realizadas 
durante a oficina, que o jogo digital possui poucas possibilidades de adaptação aos alunos com deficiência, especialmente, deficiências visuais.

O Tetris apresenta em sua interface os tetraminós, elementos que são associados à geometria, pertencendo, portanto, ao próprio objeto de conhecimento do jogo. Estas representações ajudam no aumento da capacidade de concentração, da noção espacial, e da percepção visual; além do desenvolvimento da compreensão de área a partir da composição e decomposição de figuras e de perímetro.

Pode-se concluir que o Tetris, embora seja um jogo de entretenimento, se apresenta para os docentes como uma ferramenta com alto potencial lúdico e que permite diversas aplicações, trazendo os conceitos escolares para um contexto mais próximo à cultura infantil, tornando assim a aprendizagem mais atraente e significativa.

Como estudos futuros, pretende-se realizar esta oficina com estudantes do anos iniciais, no âmbito da escola, para verificar as contribuições conceituais e limitações estruturais da utilização desta ferramenta no ensino de geometria.

\section{Referências}

Almeida, M. E. B. (2008) 'Tecnologias na Educação: dos caminhos trilhados aos atuais desafios'. Bolema (Rio Claro), v. 1,p. 99-129.

Brasil, MEC/SEF. Parâmetros curriculares nacionais: Matemática. Brasília: MEC/ Secretaria de Educação Fundamental, 1997.

Brougère, G. (2006) 'Brinquedo e cultura'. São Paulo: Cortez.

Brom, C., Preuss, M. e Klement, D. (2011) 'Are educational computer micro-games engaging and effective for knowledge acquisition at high-schools? A quasi experimental study'. Computers \& Education, 57(3), p.1971-1988.

Buckingham, D. (2010) 'Cultura Digital, Educação Midiática e o Lugar da Escolarização’ Educ. Real., Porto Alegre, v. 35, n. 3, p. 37-58, set./dez

Carr, D. et al. (2006) 'Computer Games: Text, Narrative and Play'. Cambridge: Polity.

Castells, M. (1999). 'A sociedade em rede'. São Paulo: Paz e Terra.

Castro, J. B.; Castro-Filho, J. A. (2012) 'Projeto Um Mundo de Informações: Integração de Tecnologias Digitais ao Currículo Escolar'. In: Congresso Brasileiro de Informática na Educação, 1., 2012, Rio de Janeiro. Anais... Rio de Janeiro: SBC.

Costa, L. D. (2009) 'O que os jogos de entretenimento têm que os jogos educativos não têm'.In: Anais do VIII Brazilian Symposium on Games and Digital Entertainment. Rio de Janeiro, RJ - Brazil

Del Blanco Á.; Torrente, J.; Moreno-Ger, P.; Fernández-Manjón, B. A (2009) 'General Architecture for the Integration of Educational Videogames in Standards-compliant Virtual Learning Environments'. In: Ninth IEEE International Conference on Advanced Learning Technologies ICALT, p.53-55.

Huizinga, Johan (2012) 'Homo Ludens: o jogo como elemento da cultura'. São Paulo: Perspectiva, 7 a edição.

Lemos (2010) Cibercultura, tecnologia e vida social na cultura contemporânea. Porto Alegre: Sulina.

Maia, D. L. ; Barreto, M. C. (2012) 'Tecnologias digitais na educação: uma análise das políticas públicas brasileiras'. In: Revista EF\&T.

Mayo, M. J. (2007) 'Special issue on Creating a Science of Games'. Communications of the ACM, v50(7) p.26-73.

Mattar, J. (2010) 'Games em educação: como os nativos digitais aprendem.' São Paulo: Pearson Prentice Hall..

Wauchauer, M. (2006) 'Tecnologia e inclusão social'. São Paulo: Senac. 